СТАТЬИ

УДК $630 * 165.3: 630 * 232.5: 633.877 .3$

ВЛИЯНИЕ ЭКОЛОГО-ГЕНЕТИЧЕСКИХ ФАКТОРОВ
НА МОРФОМЕТРИЧЕСКИЕ ПАРАМЕТРЫ И ДИНАМИКУ
ГОДИЧНОГО ПРИРОСТА ДРЕВЕСИНЫ
В ИСПЫТАТЕЛЬНЫХ КУЛЬТУРАХ РINUS SYLVESTRIS L.

Вахнина И.Л., Ларин В.С., Пак Л.Н.

ФГБУН «Институт природных ресурсов, экологии и криологии» Сибирского отделения Российской академии наук, Чита, e-mail: vahnina il@mail.ru

\begin{abstract}
Сведение и гибель лесов в результате рубок, пожаров и других видов воздействий, особенно за последние десятилетия, привели к очевидному сокращению их генетического разнообразия, значимых генотипов и оскуднению генофонда лесов Восточного Забайкалья. В связи с этим особую ценность представляют испытательные плантационные культуры, созданные путем размножения плюсовых деревьев (Пд), отобранных по ценным фенотипическим особенностям. Цель данной работы заключалась в анализе клонового потомства ПД сосны обыкновенной по изменчивости морфометрических параметров и динамике годичного прироста древесины в испытательных культурах. Из полученных предварительных результатов следует, что у 57,8\% клонового потомства ПД сохраняется генетическая обусловленность по скорости роста. Несмотря на то, что по некоторым показателям не у всех клонов ПД выявлены существенные отличия с контрольными деревьями, достоверно большая площадь ассимиляционной поверхности привитых деревьев позволяет заключить, что они характеризуются большей энергией протекания физиологических процессов, которые определяют формирование шишек и темпы образования биомассы. Погодичная динамика ширины годичных колец характеризуется наличием минимальных экстремумов прироста в 2003 и 2007 гг., связанных со снижением количества атмосферных осадков в эти годы. Разницы между деревьями по ширине годичных колей выявлено не было, предположительно это связано с возрастом деревьев и периодом большого роста. Оценка клонов ПД с помощью дендрохронологических методов исследования показала, что древостои II класса возраста испытывают интенсивное воздействие природных факторов среды, которое выражается в формировании экстремально низких значений ширины годичных колец в годы засух.
\end{abstract}

Ключевые слова: лесосеменная плантация, сосна обыкновенная, клоны, годичные кольца, морфометрия, климат

\title{
NFLUENCE OF ENVIRONMENTAL GENETIC FACTORS ON MORPHOMETRIC PARAMETERS AND DYNAMICS OF THE ANNUAL GROWTH OF WOOD IN PINUS SYLVESTRIS L. TEST CULTURES \\ Vakhnina I.L., Larin V.S., Pak L.N. \\ Institute of Natural Resources, Ecology and Cryology SB RAS, Chita, e-mail:vahnina_il@mail.ru
}

\begin{abstract}
Deforestation and destruction of forests as a result of logging, fires and other types of impacts, especially over the last decades, have led to an obvious reduction in their genetic diversity, significant genotypes and impoverishment of the gene pool of forests of East Transbaikalia. In this regard, test plantation crops created by propagating plus trees (PD), selected according to valuable phenotypic characteristics, are of particular value. The goal of this work was to analyze the clonal progeny of AP of pine ordinary according to the variability of morphometric parameters and the dynamics of the annual growth of wood in test cultures. From the preliminary results obtained, it follows that in $57.8 \%$ of the clonal offspring of PD, genetic dependence on the growth rate is preserved. Despite the fact that, according to some indicators, not all PD clones showed significant differences with control trees, a reliably large area of the assimilation surface of grafted trees allows us to conclude that they are characterized by higher energies of physiological processes that determine the formation of cones and the rate of biomass formation. The weather dynamics of the width of annual rings is characterized by the presence of minimal growth extrema in 2003 and 2007 associated with a decrease in the amount of precipitation in these years. There was no difference between the trees by the width of annual ruts, presumably this is due to the age of the trees and a period of high growth. Evaluation of PD clones using dendrochronological research methods showed that stands of the II age class experience an intense influence of natural environmental factors, which is expressed in the formation of extremely low values of the width of annual rings in drought years.
\end{abstract}

Keywords: forest seed plantation, Scots pine, clones, tree rings, morphometry, climate

Сведение и гибель лесов в результате рубок, пожаров и других видов воздействий, особенно за последние десятилетия, привели к очевидному сокращению их генетического разнообразия, значимых генотипов и оскуднению генофонда лесов Восточного Забайкалья. Сохранение остав- шейся совокупности генных вариаций имеет серьезное значение для сбережения, рационального использования и репродукции экологически и экономически необходимых популяций, групп популяций и видов [1-3].

Все вышесказанное служит причиной продолжения ранее начатых работ по фор- 
мированию постоянной лесосеменной базы сосны обыкновенной, которая является ценной лесообразующей породой данной территории. На ее долю приходится порядка 9\% лесопокрытой площади Восточного Забайкалья (по данным государственного лесного реестра на 01.01.2018 г.). Учитывая, что сосна является основным источником древесины исследуемой территории, этот вид может использоваться для создания плантаций на повышенную семенную и стволовую продуктивность. В связи с этим особую ценность представляют испытательные плантационные культуры, созданные путем размножения плюсовых деревьев (ПД), отобранных по ценным фенотипическим особенностям [4].

Существенным недостатком селекционной работы является то, что фенотипические признаки ПД не всегда соответствуют генотипу особи. Тем не менее отбор ПД по их фенотипу в какой-то мере оправдывается вероятностью того, что какая-либо ценная особенность этих деревьев проявится в их семенном потомстве значительно больше, чем в потомстве деревьев, не обладающих этой особенностью $[5,6]$.

Эффективность селекционных работ на плантациях, созданных путем вегетативного размножения (прививкой) ПД, снимает многие проблемы селекционно-генетической оценки, возникающие при испытании семенного потомства. Это связано с тем, что на ЛСП создаются сходные условия светового и минерального питания, вводятся повторности, клоны размещаются по определенной схеме. В результате здесь складываются условия, позволяющие фактически оценивать клоны ПД по целому ряду признаков [7-9], которые могут быть скрыты в высокополнотном естественном насаждении, на этапе отбора.

На территории Восточного Забайкалья первый опыт по отбору ПД и созданию лесосеменной плантации (ЛСП) путем их вегетативного размножения был проведен в начале 1990-х гг. сотрудниками лаборатории лесных экосистем Института природных ресурсов СО РАН (ныне ИПРЭК СО РАН) под руководством В.П. Бобринева и при непосредственном участии Л.Н. Пак. Ими было отобрано и аттестовано 52 ПД сосны обыкновенной в Читинском лесничестве. Здесь же была заложена первая опытная, клоновая плантация площадью 10 га.

Цель исследования: анализ клонового потомства ПД сосны обыкновенной по изменчивости морфометрических параметров и динамики годичного прироста древесины в испытательных культурах.

\section{Материалы и методы исследования}

Исследования проводились в 2014 г. на клоновой ЛСП сосны обыкновенной первого порядка (N 51 49', E $113^{\circ} 08^{\prime}, 700$ м над у.м.) в Читинском лесничестве на территории Восточного Забайкалья. Культуры создавались равномерной посадкой, с размещением клонов и повторностей (рамет) 125 растений на 1 га плантации. Подробное описание закладки культур было приведено ранее $[10,11]$.

Морфометрические и дендрохронологические исследования выполнены согласно общепринятым методам $[12,13]$. Изучению подлежали следующие морфометрические показатели: диаметр и высота ствола, возраст и длина хвои, плодоношение. Всего обследовано 21 клон ПД, 121 рамет. В качестве контроля были исследованы 14 непривитых, сопоставимых по возрасту деревьев сосны обыкновенной, произрастающих в сходных условиях за пределами ЛСП. Для определения динамики ширины годичных колец (ШГК) у каждого дерева по двум радиусам брали керны.

\section{Результаты исследования и их обсуждение}

Результаты статистических расчетов морфометрических данных приведены в таблице. К 30-летнему возрасту клоны имели среднюю высоту 7,4 м. По клонам данный показатель колебался от 6,8 до 8,1 м. Изменчивость высоты была небольшая, составляла всего 4,1\%. Наибольшая высота отмечалась у клонов: $24 ; 32 ; 37-38 ; 45$, что охватывало только 23,8 \% от числа всех клонов ПД. Клоны, не превышающие среднюю высоту по ЛСП, составляли $38 \%$.

Анализ морфометрических данных клонов ПД и контрольных деревьев показал, что средняя высота клонов была достоверно больше (от 6,82 $\pm 1,04$ м до 8,1 $\pm 0,24$ м), чем у непривитых деревьев $(6,57 \pm 0,44$ м).

Анализ динамики иирины годичных колец (ШГК). По результатам измерения средний диаметр клонов в культурах составил 15,1 см. Изменчивость этого показателя была небольшой - 6,1%. По диаметру, наибольшее превышение среднего показателя по культурам, отмечалось у клонов: 26; 4243. Клоны, не превышающие средний диаметр по ЛСП, составляли 47,6\%. Средний диаметр клонов был достоверно больше (от $13,74 \pm 1,02 \mathrm{~cm}$ до $17,4 \pm 3,77 \mathrm{~cm}$ ), чем у непривитых деревьев $(14,89 \pm 1,19$ см). 


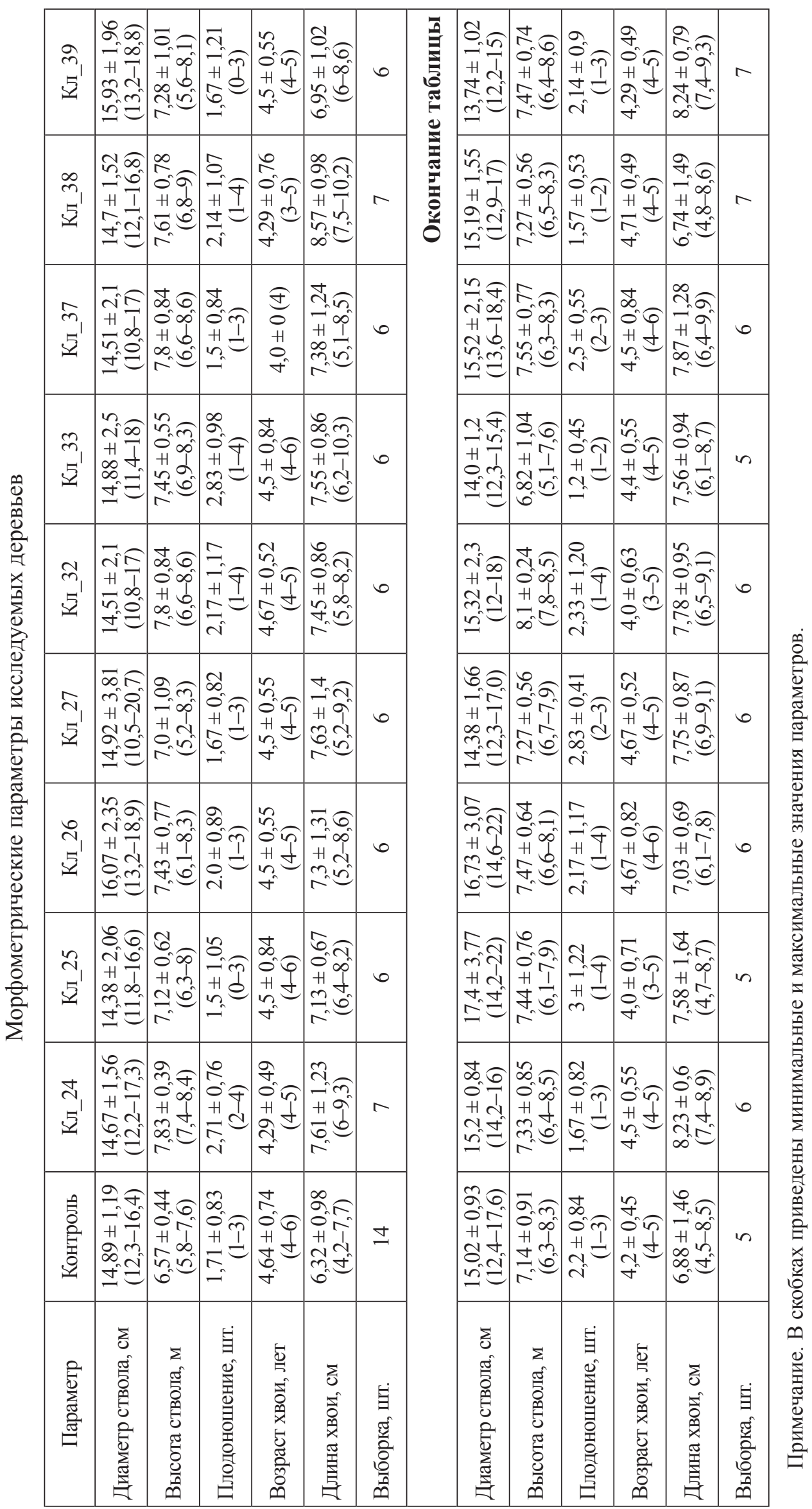


Длина хвои у клонов изменялась незначительно, уровень изменчивости составил 6,5 \%. Длинную хвою имели клоны: $38 ; 41$; 52 , т.е. 14,2\% всех клонов. Клоны, имеющие хвою меньше средней по ЛСП, составляли $38 \%$. У контрольных деревьев в среднем длина хвои достоверно отличалась от клонов, она составляла $6,32 \pm 0,98$ см, в то время как у клонов варьировала от $6,74 \pm 1,49$ см до 8,57 $\pm 0,98$ см.

Небольшая часть деревьев из исследуемой выборки характеризовалась лучшим плодоношением (14,2\%). Это клоны 24; 42; 44. Изменчивость данного показателя была существенной 24,7\%. Лишь у 38,0\% деревьев данный показатель был сопоставим с контролем.

Возраст хвои не имел значимых различий по сравниваемым выборкам, это обусловлено тем, что данный параметр не зависит от генетической предрасположенности, а связан с влиянием экологических факторов среды.

По результатам измерения ширины годичных колец построены 28 индивидуальных древесно-кольцевых хронологий, их продолжительность составила от 12 до 15 лет (рис. 1). Они показали, что для всех исследуемых приростов характерно формирование наиболее широких годичных колец в 2002 , 2005, 2008 и 2009 гг, а узких - в 2001, 2003,
2007 и 2011 гг. Что согласуется с данными по исследуемой территории, полученными ранее $[14,15]$. Для всех кернов характерно наличие минимальных экстремумов прироста в 2003 и 2007 гг. Сравнительный анализ средних значений ШГК у клонов ПД не показал достоверных отличий размеров годичных колец по сравнению со средней ШГК контрольных деревьев.

За период исследования по всем сериям средние значения ШГК варьировали в пределах от 3,8 $\pm 1,64$ мм до 5,4 $\pm 1,83$ мм, максимальный прирост составил 8,9 мм, a минимальный - 0,8 мм. Такие высокие значения ШГК связаны, прежде всего, с возрастом деревьев, для которых, так называемый, «период большого роста», еще не завершен. Дисперсия по выборкам колебалась от 2,47 до 5,97.

Статистический анализ в программе TSAPWin показал высокое сходство индивидуальных графиков (Glk) и максимальный уровень синхронности (GSL) между ними. Среднее значение межсериального коэффициента корреляции составило - 0,97, при минимальном - 0,87, что позволило усреднить данные и получить обобщенную древесно-кольцевую хронологию INST по абсолютным значениям ШГК, отражающую влияние внешних факторов среды на радиальный прирост деревьев.
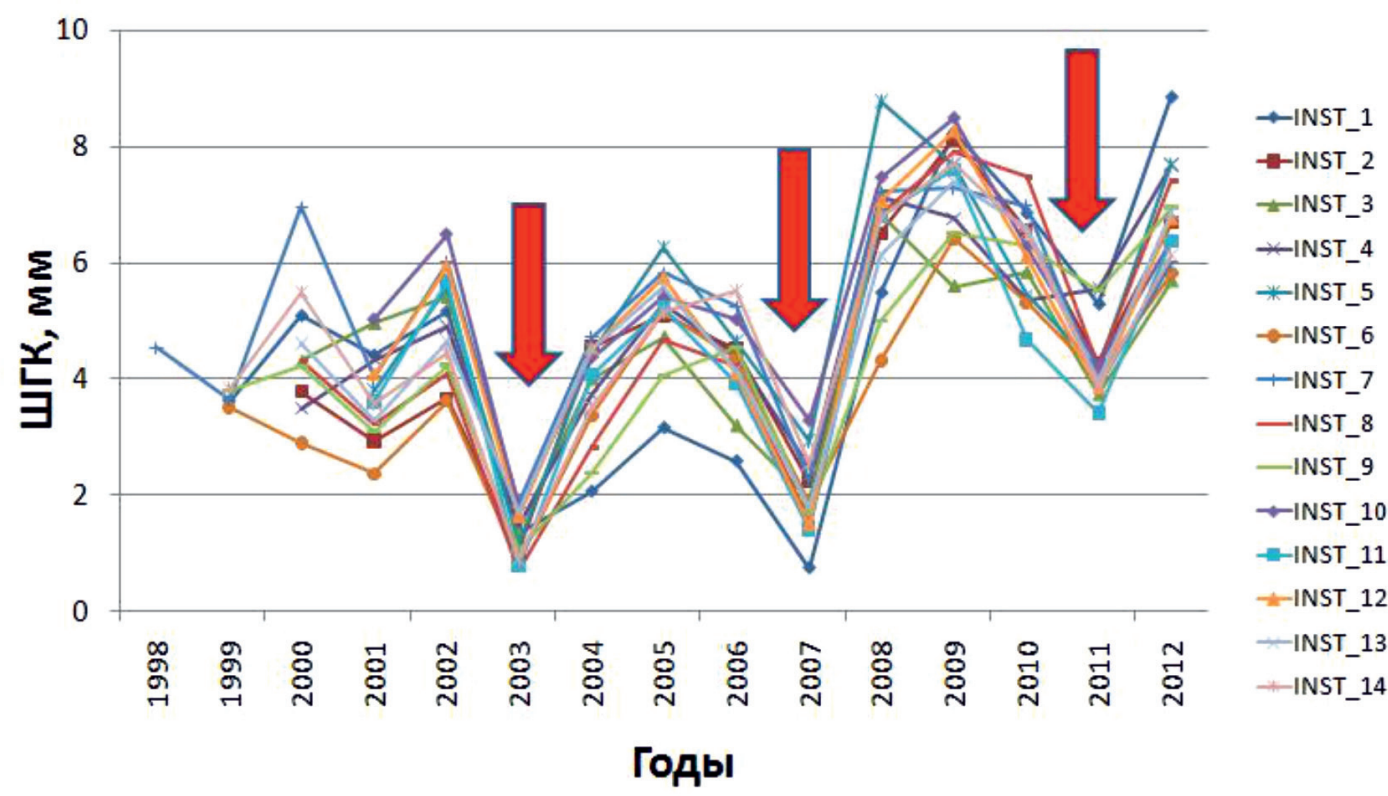

Рис. 1. Индивидуальные серии ширины годичных колец на клоновой ЛСП сосны обыкновенной первого порядка (среднее по двум радиусам) 
Анализ климатического отклика выполнен с помощью корреляционного анализа между полученной обобщенной древесно-кольцевой хронологией и среднемесячными значениями атмосферных осадков за период, в течение которого возможно их влияние на радиальный прирост древесины. Использованы данные метеорологической станции г. Чита (N 52 $03^{\prime}$, E $\left.113^{\circ} 29^{\prime}\right)$. Доверительный интервал коэффициентов корреляции (при $\mathrm{p}<0,05)$ лежит за пределами значений от 0,46 до $-0,46$.

Расчет показал, что значимое влияние на радиальный прирост деревьев, произрастающих на клоновой ЛСП сосны обыкновенной первого порядка, оказывают среднемесячные атмосферные осадки мая и июня $(\mathrm{R}=0,62$ и $\mathrm{R}=0,61$ соответственно) (рис. 2). Одинаковые значения коэффициента корреляции $(\mathrm{R}=0,61)$ получены для годовой суммы осадков и суммы осадков за период вегетации (с мая по сентябрь), что связано с выпадением подавляющего количества атмосферных осадков в исследуемом районе в теплый период года.

Несмотря на сходные показатели значимых коэффициентов корреляции для исследуемых периодов, при сравнении динамики размеров ШГК и атмосферных осадков было отмечено, что для отдельных лет определяющее значение оказывают, прежде всего, осадки первой половины периода вегетации (рис. 3). Например, в 2002 г., выявлены высокие значения прироста (4,9 мм), несмотря на то, что сумма осадков периода с мая по сентябрь была на уровне 2003 г. (223 и 224 мм), когда прирост был экстремально низким (1,5 мм). Это связано с тем, что в 2002 г. атмосферные выпадения в первой половине вегетации были почти в 16 раз выше по сравнению с тем же периодом в 2003 г. Подобная ситуация отмечается и для 2010 г. Поэтому в корреляционный анализ дополнительно были включены средние значения суммы атмосферных осадков июля и июня, которые позволили выявить максимальные значения показателя $(\mathrm{R}=0,69)$. Достоверной связи приростов с атмосферными осадками сентября предшествующего года не выявлено $(\mathrm{R}=0,21)$.

\section{Заключение}

Из полученных предварительных результатов следует, что у $57,8 \%$ клонового потомства ПД сохраняется генетическая обусловленность по скорости роста. Несмотря на то, что по некоторым показателям не у всех клонов ПД выявлены достоверные отличия с контрольными деревьями, достоверно большая площадь ассимиляционной поверхности привитых деревьев позволяет заключить, что они характеризуются большей энергией протекания физиологических процессов, которые определяют формирование шишек и темпы образования биомассы. Погодичная динамика ШГК характеризуется наличием минимальных экстремумов прироста в 2003 и 2007 гг, связанных со снижением количества атмосферных осадков в эти годы.

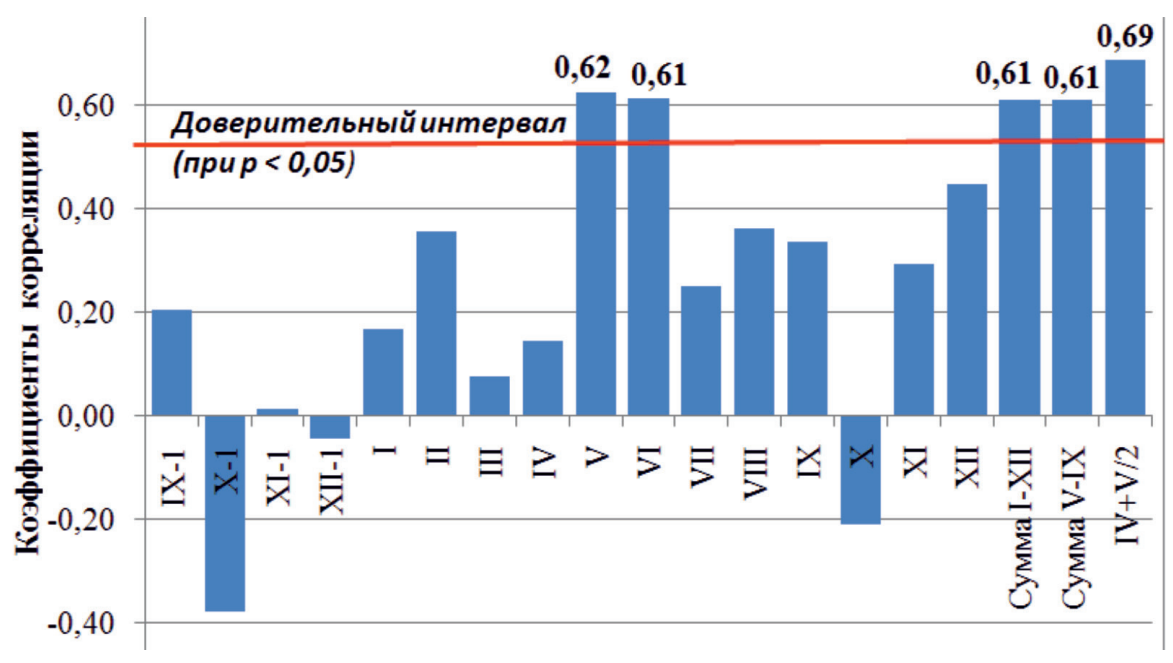

Рис. 2. Коэффициенты корреляичи между обобщзенной древесно-кольцевой хронологией (INST) и атмосферными осадками за период с 1999 по 2012 г. 


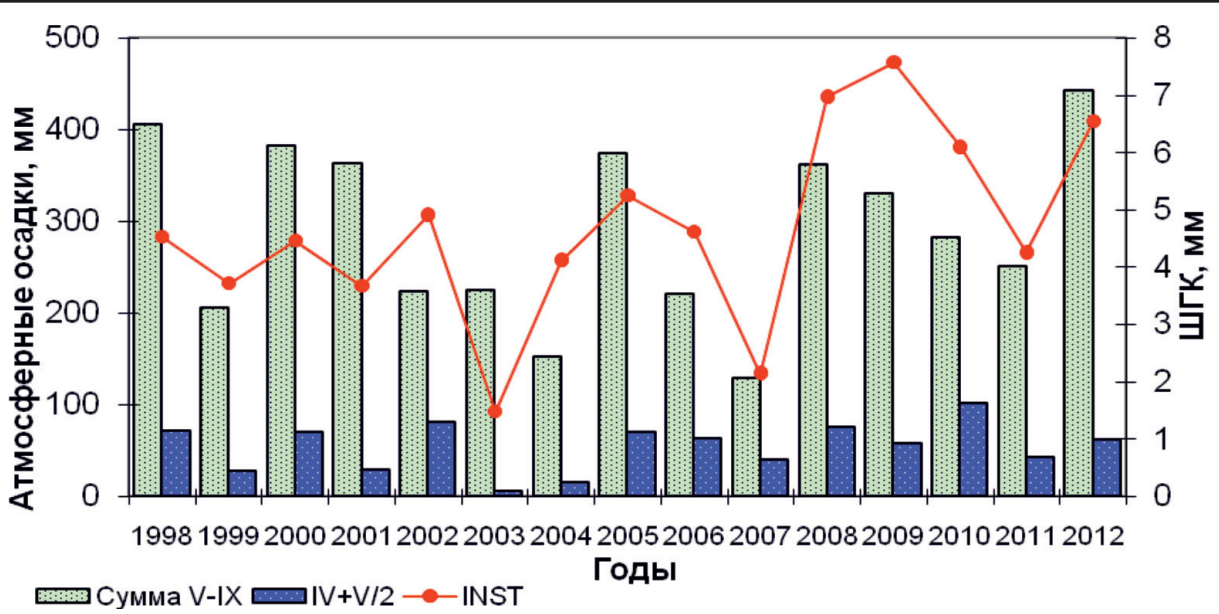

Рис. 3. Динамика приростов обобщенной древесно-кольцевой хронологии и значений атмосферных осадков за отдельные периоды

Разницы между деревьями по ШГК выявлено не было, предположительно это связано с возрастом деревьев и периодом большого роста. Оценка клонов ПД, произрастающих на ЛСП сосны обыкновенной первого порядка, с помощью дендрохронологических методов исследования показала, что древостои II класса возраста испытывают интенсивное воздействие природных факторов среды, которое выражается в формировании экстремально низких значений ширины годичных колец в годы засух. Особенно губительно на деятельности камбия сказывается снижение атмосферных осадков в первой половине периода вегетации (май - июнь).

\section{Список литературы / References}

1. Тараканов В.В., Демиденко Я.Н., Ишутин Н.Т., Бушков В.В. Селекционное семеноводство сосны обыкновенной в Сибири. Новосибирск: Наука, 2001. 196 с.

Tarakanov V.V., Demidenko Y.N., Ishutin N.T., Bushkov V.V. Selection seed production of common pine in Siberia. Novosibirsk: Nauka, 2001. 196 p. (in Russian).

2. Ефимов Ю.П. Семенные плантации в селекции и семеноводстве сосны обыкновенной. М.: Исток, 2010. 253 с.

Efimov Yu.P. Seed plantations in the selection and seed production of Scots pine. M.: Istok, 2010. 253 p. (in Russian).

3. Иозус А.П., Морозова Е.В. Основные направления селекции сосны обыкновенной на устойчивость и долговечность в сухой степи Нижнего Поволжья // Современные проблемы науки и образования. 2015. № 2-1. [Электронный pecypc]. URL: http://science-education.ru/ru/article/ view?id=20571 (дата обращения: 05.11.2019).

Iozus A.P., Morozova E.V. The main directions of selection of Scots pine for stability and durability in the dry steppe of the Lower Volga // Modern problems of science and education. 2015. № 2-1. [Electronic resource]. URL: http://science-education.ru/ru/article/view?id=20571 (date of access: 05.11.2019) (in Russian).

4. Бессчетнова Н.Н., Бессчетнов В.П. Изменчивость морфометрических признаков хвои на клоновой плантации плюсовых деревьев сосны обыкновенной (Pinus sylvestris L.)// Вавиловский журнал генетики и селекции. 2017. T. 21. № 2. C. 198-206. DOI: 10.18699/VJ17.237.

Besschetnova N.N., Besschetnov V.P. Variability of morphometric signs of needles on a clone plantation of plus trees of Scots pine (Pinus sylvestris L.) // Vavilovsky Journal of Genetics and Selection. 2017. Vol. 21. № 2. P. 198-206 (in Russian).

5. Видякин А.И. Эффективность плюсовой селекции древесных растений // Хвойные бореальной зоны. 2010. T. XXVII. № 1-2. C. 18-24.

Vidyakin A.I. Efficiency of positive selection of woody plants // Conifers of the boreal zone. 2010. T. XXVII. № 1-2. P. 18-24 (in Russian).

6. Раевский Б.В. Особенности вегетативного роста клонов сосны обыкновенной в Карелии // Известия высших учебных заведений. Лесной журнал. 2013. № 4. С. 7-15.

Raevsky B.V. Features of the vegetative growth of clones of Scots pine in Karelia // Forestry Journal. 2013. № 4. P. 7-15 (in Russian).

7. Тихонова И.В., Тараканов В.В., Кнорре А.А. Вклад генотипических и метеорологических факторов в изменчивость годичных приростов древесины на клоновой плантации сосны // Экология. 2012. № 3. С. 163-169.

Tikhonova I.V., Tarakanov V.V., Knorre A.A. Contribution of genotypic and meteorological factors to the variability of annual growths of wood on a clone pine plantation. Russian Journal of Ecology. 2012. № 3. P. 179-184. DOI: 10.1134/ S1067413612030150.

8. Криворотова Т.Н., Прохорова Е.В., Шейкина О.В., Новиков П.С. Оценка клоновых потомств плюсовых деревьев сосны обыкновенной на коллекционноматочном участке республики Марий Эл // Известия Оренбургского государственного аграрного университета. 2013. № 1 (39). С. 18-20.

Krivorotova T.N., Prokhorova E.V., Sheikina O.V., Novikov P.S. Evaluation of the clonal offspring of plus trees of Scots pine on the collection site of the Mari El Republic // Izvestiya Orenburgskogo gosudarstvennogo agrarnogo universiteta. 2013. № 1 (39). P. 18-20 (in Russian).

9. Раевский Б.В. Особенности вегетативного роста клонов сосны обыкновенной в Карелии // Известия высших учебных заведений. Лесной журнал. 2013. № 4 (334). C. $7-15$.

Raevsky B.V. Features of the vegetative growth of clones of Scots pine in Karelia // Forestry Journal. 2013. № 4 (334). P. $7-15$ (in Russian).

10. Бобринев В.П., Пак Л.Н. Лесные стационарные исследования в Забайкальском крае. Чита, 2011. 492 с. 
Bobriniev V.P., Pak L.N. Forest stationary research in the Trans-Baikal Territory. Chita, 2011. 492 p. (in Russian).

11. Пак Л.Н., Бобринев В.П. Закладка лесосеменной плантации сосны в Забайкальском крае // Аграрная наука. 2014. № 3. C. 12-13.

Pak L.N., Bobrinov V.P Laying of Forest Seed of Pine Plantation in Zabaikalsky Krai // Agrarian science. 2014. № 3. P. $12-$ 13 (in Russian).

12. Мамаев C.A. Формы внутривидовой изменчивости древесных растений (на примере семейства Pinaceae на Урале). М.: Наука, 1972. 284 с.

Mamaev S.A. Forms of intraspecific variability of woody plants (for example, the pine family in the Urals). M.: Nauka, 1972. 284 p. (in Russian).

13. Methods of dendrochronology. Application in the Environmental Science. Eds. Cook E.R., Kairiukstis L.A. Dordrecht; Boston; London: Kluwer Acad. Publishers, 1990. 394 p.
14. Вахнина И.Л. Древесно-кольцевая хронология по сосне обыкновенной в региональных условиях Восточного Забайкалья // Хвойные бореальной зоны. 2013. Т. 31. № 1-2. C. $54-56$.

Vakhnina I.L. Tree-ring chronology of common pine in the regional conditions of East Transbaikalia// Khvoynyye boreal'noy zony. 2013. V. 31. № 1-2. P. 54-56 (in Russian).

15. Вахнина И.Л., Обязов В.А., Замана Л.В. Динамика увлажнения в степной зоне Юго-Восточного Забайкалья с начала XIX столетия по кернам сосны обыкновенной // Вестник Московского университета. Серия 5: География. 2018. № 2. C. 28-33.

Vakhnina I.L., Obyazov V.A., Zamana L.V. Dynamics of humidification in the steppe zone of Southeastern Transbaikalia since the beginning of the 19th century evidenced by the cores of Scots pine // Vestnik Moskovskogo universiteta. Seriya 5: Geografiya. 2018. № 2. P. 28-33 (in Russian). 